\title{
Verticillium dahliae Race 2-Specific PCR Reveals a High Frequency of Race 2 Strains in Commercial Spinach Seed Lots and Delineates Race Structure
}

\author{
Dylan P. G. Short, Suraj Gurung, Karunakaran Maruthachalam, Zahi K. Atallah, and Krishna V. Subbarao
}

Department of Plant Pathology, University of California, Davis, 1636 E Alisal St., Salinas 93905.

Accepted for publication 22 January 2014.

\begin{abstract}
Short, D. P. G., Gurung, S., Maruthachalam, K., Atallah, Z. K., and Subbarao, K. V. 2014. Verticillium dahliae race 2-specific PCR reveals a high frequency of race 2 strains in commercial spinach seed lots and delineates race structure. Phytopathology 104:779-785.

Two pathogenic races of Verticillium dahliae have been described on lettuce and tomato. Host resistance to race 1 is governed by plant immune receptors that recognize the race 1-specific fungal effector Ave1. Only partial resistance to race 2 exists in lettuce. Although polymerase chain reaction (PCR) assays are available to identify race 1 , no complementary test exists to positively identify race 2 , except for lengthy pathogenicity assays on host differentials. Using the genome sequences of two isolates of $V$. dahliae, one each from races 1 and 2, we identified potential markers and PCR primers to distinguish the two races. Several primer pairs based on polymorphisms between the races were designed and tested on reference isolates of known race. One primer pair, VdR2F-VdR2R, consistently yielded a $256-b p$ amplicon in all race 2 isolates exclusively. We screened DNA from $677 \mathrm{~V}$. dahliae isolates, including 340 from spinach

seedlots, with the above primer pair and a previously published race 1 -specific primer pair. DNA from isolates that did not amplify with race 1 -specific PCRs amplified with the race 2 -specific primers. To validate this, two differential lines of lettuce were inoculated with 53 arbitrarily selected isolates from spinach seed and their pathogenicity and virulence were assessed in a greenhouse. The reactions of the differential cultivars strongly supported the PCR data. $V$. dahliae race structure was investigated in crops in coastal California and elsewhere using primers specific to the two races. All artichoke isolates from California were race 1, whereas nearly all tomato isolates were race 2. Isolates from lettuce, pepper, and strawberry from California as well as isolates from spinach seed from two of four countries comprised both races, whereas only race 2 was observed in cotton, mint, olive, and potato. This highlights the importance of identifying resistance against race 2 in different hosts. The technique developed in this study will benefit studies in ecology, population biology, disease surveillance, and epidemiology at local and global scales, and resistance breeding against race 2 in lettuce and other crops.
\end{abstract}

Verticillium dahliae is a soilborne plant pathogen that causes an economically significant wilt disease in a range of important plant species. The resting structures of $V$. dahliae, melanized microsclerotia, play a major role in the disease cycle because they enable the fungus to lie dormant for several years in seed, soil, and plant debris (31). Fungal disease dispersal may be attributed to human activities (16) and movement of $V$. dahliae via infested seed $(13,35)$ and soil (12) may occur frequently, resulting in dispersal over long distances. Migration of $V$. dahliae between agricultural regions via microsclerotia, particularly from populations with high genetic diversity, has likely contributed to local epidemics and genotypic variability on a global scale (1).

Plants have evolved resistant genes that encode receptors that recognize molecular patterns of proteins of viruses, bacteria, and fungi (9), as well as secreted effectors of pathogens $(6,37)$. Homologous plant resistance $(R)$ genes that confer resistance to $V$. dahliae race 1 have been identified in cotton, lettuce, tomato, and sunflower $(15,19,32,38)$. These single dominant $R$ genes, which confer resistance to $V$. dahliae race 1 , have been successfully deployed in commercial varieties of tomato (Vel) (32) and lettuce (Vrl) (19). V. dahliae race 1 strains possess the gene Avel,

Corresponding author: K. V. Subbarao; E-mail address: kvsubbarao@ucdavis.edu

* The $\boldsymbol{e}$-Xtra logo stands for "electronic extra" and indicates that the online version contains one supplementary table.

First and second authors contributed equally.

http://dx.doi.org/10.1094/PHYTO-09-13-0253-R

(C) 2014 The American Phytopathological Society which encodes a virulence factor that acts on plants lacking the plant immune receptor-encoding Vel gene (8). Cross-pathogenicity of $V$. dahliae race 1 isolates on different hosts, such as lettuce and tomato, has been documented (25). Currently, only partial resistance to $V$. dahliae race 2 has been observed in tomato (3) and lettuce (18).

Knowledge of the physiological differences between the races is limited (28). The potential origin of race 2, which may have evolved through the loss of the avirulence gene (8), remains unsettled. Analyses of $V$. dahliae populations have highlighted the extent of overlapping global distributions of both races $(14,25$, 29). In addition to providing data on local and global population structure, knowledge of pathogen population genetics and epidemiology influence the approach to breeding resistance in hosts against both races (27).

Microsclerotia-infested spinach seed has been identified as a likely source of $V$. dahliae introductions into coastal California agroecosystems, due to the high planting density of infested spinach seed $(1,2,13)$. Nearly all spinach seed planted in California is imported from various Northern European countries and from Washington State in the United States. Even though spinach seed carries V. dahliae, the crop is harvested within 4 weeks after seeding, well before symptom onset. Thus, the disease has never been a problem in spinach production fields. However, the pathogen introduced into fields by spinach seed affects subsequent crops that follow spinach, including lettuce. Currently, no information is available on the race structure of spinach-seedborne V. dahliae.

Polymerase chain reaction (PCR) techniques for the characterization of races in $V$. dahliae are valuable, because screening 
disease reactions on plant differential cultivars is time consuming and resource intensive. Molecular techniques that rapidly distinguish races are convenient for population biology, disease surveillance, and resistance breeding. Prior to the identification of the gene encoding the race 1-specific fungal effector (Avel), the PCR primers $\operatorname{Tr} 1$ and $\operatorname{Tr} 2(25,34)$ were used to positively identify race 1 isolates. Subsequently, it has been shown that both the Avel locus and the $\operatorname{Tr} 1$ and $\operatorname{Tr} 2$ primer binding sites reside within a unique $50-\mathrm{kb}$ region specific to $V$. dahliae race $1(8,34)$. However, currently, there is no complementary assay to positively identify race 2 isolates of $V$. dahliae. Therefore, the objectives of the present study were to (i) develop and validate a robust PCR assay to identify race 2 isolates, (ii) apply the PCR to a set of isolates derived from commercial spinach seed lots from different countries to document the frequency of race 2 in spinach seed, (iii) assess the correlation between molecular data and virulence assays on two host differentials in lettuce, and (iv) apply the race 1- and 2-specific PCRs to isolates collected from crops in coastal California and from representative samples of a global collection of $V$. dahliae from a variety of crops to investigate the utility of the markers and determine the prevalence of the two races.

\section{MATERIALS AND METHODS}

Sources of isolates and DNA extraction. In total, 677 isolates of $V$. dahliae from infected artichoke, cotton, eggplant, lettuce, olive, pepper, potato, mint, tomato, strawberry, spinach, and watermelon from nine countries were included in the current study (Supplementary Table 1). These isolates were a subsample of a global collection of $V$. dahliae (K. V. Subbarao, University of California [UC] Davis). Briefly, isolates were single spored on potato dextrose agar (PDA), transferred into glass flasks containing $50 \mathrm{ml}$ of potato dextrose broth (PDB), and incubated on laboratory benches $\left(23 \pm 1^{\circ} \mathrm{C}\right)$. After 1 week, mycelia were harvested from PDB and rinsed thoroughly with double-sterilized distilled water, dried using paper towels, and stored at $-80^{\circ} \mathrm{C}$. Later, mycelia were lyophilized and ground to fine powder using a high-speed mixer mill (Model MM301; Retsch Inc., Newtown, PA). Genomic DNA was extracted using a FastDNA Kit (MP Biomedicals, Solon, $\mathrm{OH}$ ) and quantified using a NanoDrop (Thermo Scientific Inc., Waltham, MA). DNA samples were adjusted to a final concentration of $10 \mathrm{ng} / \mu \mathrm{l}$ before being used as templates for PCR.

Comparison of race 1 and 2 genomes and development of race 2 -specific primer. The genome of $V$. dahliae race 1 strain Ls16 from lettuce was sequenced (26) to compare with the genome of $V$. dahliae race 2 strain Ls17 (23). Briefly, genomic DNA was obtained from protoplasts of Ls16 grown on PDA using an Omniprep kit (G-Biosciences, St. Louis). Paired-end sequences of Ls16 were generated from two different libraries (insert sizes of 350 and $500 \mathrm{bp}$ ) using reads from an Illumina Genome Analyzer IIx (Illumina, Inc., San Diego, CA). In all, $\approx 33 \mathrm{Mb}$ of sequence $(\approx 95 \%$ of the sequenced genome) was recovered through the de novo assembly software NGS Cell 3.0 (CLCBio, Cambridge, MA). The total number of contigs in the genome was 4,039 and their N50 length was $342.95 \mathrm{~kb}$. A web-based platform, the Verticillium Genome Database (VGD), was developed for Verticillium through the Comparative Fungal Genetics Platform (CFGP) (30).

Primer design and validation. Using the VGD through the CFGP, putative fixed polymorphism substitutions between strains Ls16 and Ls17 were identified, including gain and loss of genes, indels, and single-nucleotide polymorphisms (SNPs). Nine primer pairs that selectively targeted Ls17 alleles were designed (data not shown) and a preliminary PCR screen was performed using DNA from isolates of $V$. dahliae race 1 (Ls16 and Le1087) and race 2 (Ls17 and Le1103) (see below for specific conditions). The primer pair VdR2F (ACTTAACGAAAGCATGCGC) and VdR2R
(CTTGACTTGCCGGCTCC) consistently amplified DNA from race 2 isolates. These primers target a 256-bp region located on the exonic region of the $V D A G \_05863.1$ gene (http://www. broadinstitute.org/annotation/genome/verticillium_dahliae/MultiHome. $\mathrm{html}$ ), an open reading frame (ORF) encoding a hypothetical protein located on chromosome 4 of the Ls17 genome (Supercontig 11: 724355-725313). These primers, in addition to the primers VdAve1F (AAGGGGTCTTGCTAGGATGG) and VdAve1R (TGAAACACTTGTCCTCTTGCT) (8) and Tr1 (TGA AGTAGCCGATAGCTTTGTCTTGCC) and Tr2 (TGTCTGGAT TAATCGCCGCAATAGA) (34), were tested with DNA from 13 additional isolates: Sb52, Le1087, Cs1616, Sb50, 84, Cl1, PP48, Ls775, PD494, G2D5, Cb86.7.2, VD57, and Sm1.

PCR and gel electrophoresis conditions. PCR determination of $V$. dahliae races was performed using three primer pairs: VdAve1F and VdAve1R, Tr1 and Tr2, and VdR2F and VdR2R. PCRs using primer pairs $\operatorname{Tr} 1-\operatorname{Tr} 2$ and Ave1F-Ave1R were performed as previously described $(8,25)$. PCR amplifications with VdR2F-VdR2R were performed in $25-\mu$ l reaction volumes containing $10 \mu \mathrm{l}$ of sterile distilled water, $1 \mu \mathrm{l}$ of $10 \mathrm{ng} / \mu \mathrm{l}$ genomic DNA, $12 \mu \mathrm{l}$ of $2 \times$ GoTaq master mix, (Promega Corp., Madison, $\mathrm{WI}$ ), and $1 \mu \mathrm{l}$ of each primer at a concentration of $10 \mu \mathrm{M}$. Each PCR was performed using a PTC-100 thermocycler (MJ Research, Inc., Waterman, MA) programmed with the following thermoprofile: $2 \mathrm{~min}$ of initial denaturation at $94^{\circ} \mathrm{C} ; 35$ cycles of $1 \mathrm{~min}$ at $94^{\circ} \mathrm{C}, 1 \mathrm{~min}$ at $64^{\circ} \mathrm{C}$, and $1 \mathrm{~min}$ at $72^{\circ} \mathrm{C}$; and $10 \mathrm{~min}$ at $72^{\circ} \mathrm{C}$. SYBRGold $(5 \mu \mathrm{l})$ (Invitrogen Corporation, Carlsbad, CA) was added to PCR amplicons, which were separated in $1.5 \%$ (wt/vol) agarose gels in $0.5 \times$ Tris-borate-EDTA buffer $(0.089 \mathrm{M}$ Tris-borate, $0.089 \mathrm{M}$ boric acid, and 0.002 M EDTA). A 100-bp DNA ladder (Invitrogen Corporation) was used as a size marker and gels were visualized on a High-Performance Transilluminator (Ultra-violet Products, Ltd., Upland, CA). The Ave1-specific primers in conjunction with the race 2-specific primers were used in PCRs with DNA from a total of $677 \mathrm{~V}$. dahliae isolates from the following: artichoke from California $(n=35)$; cotton from Australia, China, and Turkey $(n=25)$; eggplant from Italy and the United States $(n=2)$; lettuce from California $(n=157)$; mint from Washington $(n=16)$; olive from Italy, the Maltese Archipelago, and Turkey ( $n=19)$; pepper from California $(n=12)$; potato from Washington $(n=13)$; spinach seed from Chile $(n=$ $5)$, Denmark $(n=87)$, the Netherlands $(n=32)$, and Washington $(n=217)$; strawberry from California $(n=21)$; sunflower from North Dakota $(n=5)$; tomato from California $(n=31)$; and watermelon from the United States $(n=1)$.

Sequencing of VdR2F-VdR2R amplicons. To verify the identity of the PCR amplicons, 67 arbitrarily chosen samples were sequenced using VdR2F and VdR2R at the UC Davis DNA Sequencing Facility. Sequences were edited and aligned with reference sequence data from Ls17 using MEGA 5.1 (24).

Virulence assays using lettuce differentials. Two differential cultivars of lettuce, 'Salinas' and 'La Brillante', were used to characterize the races of $V$. dahliae (36). Race 1 isolates caused Verticillium wilt in Salinas but disease severity $\leq 2.0$ in La Brillante, whereas $V$. dahliae race 2 caused severe symptoms on both cultivars. We hypothesized that isolates of $V$. dahliae yielding amplicons using VdR2F-VdR2R would also cause severe disease symptoms on both Salinas and La Brillante. To test this hypothesis, $53 \mathrm{~V}$. dahliae isolates from spinach seed, along with two isolates of known races Ls16 and Ls17 (25), were tested against the two differential lettuce cultivars in the greenhouse. Two separate experiments were conducted in the greenhouse using procedures described previously $(5,20,36)$. Briefly, seed of each lettuce cultivar were sown in 200-well plug trays (Hummert Int., St. Louis) filled with Sunshine Mix No. 4 (Sun Gro, Agawam, MA). Lettuce seedlings were inoculated at 2 weeks after emergence by saturating the soil in each well of the plug trays with 5 to $10 \mathrm{ml}$ of spore suspension $\left(2 \times 10^{8} \mathrm{conidia} / \mathrm{ml}\right)$. Two additional 
inoculations with each isolate were done 1 and 2 weeks after the first inoculation. Plants were then transferred into 0.5-liter foaminsulated cups filled with a pasteurized sand/potting soil mixture $(2: 1, \mathrm{vol} / \mathrm{vol})$. Each of the lettuce cultivar-isolate treatments, including the controls, was arranged in a randomized complete block design with three replications and three samples in each replication. Control plants were treated with sterilized distilled water. Plants were incubated on greenhouse benches for 8 weeks after the final inoculation, uprooted, and washed free of soil, and the roots and crowns were longitudinally cut to evaluate Verticillium wilt severity. The extent of plant infection according to root and crown discoloration in inoculated and control plants was rated on a 0 -to- 5 scale, where $0=$ no vascular discoloration; $1=1$ to $25 \%$ of the vascular tissue exhibiting discoloration; $2=26$ to $50,3=51$ to 75 , and $4=76$ to $100 \%$ discoloration in the absence of foliar symptoms; and $5=100 \%$ discoloration and the presence of foliar symptoms typical of Verticillium wilt (20). Symptomatic root and crown tissues were washed, surface disinfested using distilled water and 5\% bleach, dissected, and plated on NP-10 medium (22). After 10 to 14 days of incubation at ambient temperature, plates were examined under a dissecting microscope for the presence of $V$. dahliae characteristics such as microsclerotia, verticillate conidiophores, and hyaline conidia in each plate.

Statistical analysis of virulence data. Because we used an ordinal disease rating scale to assess the Verticillium wilt severity on lettuce cultivars, nonparametric data analyses (33) were performed using SAS (SAS Institute, Cary, NC), as described previously (20). In addition, analyses of variance examined isolate, cultivar, and isolate-cultivar interactions, and least square means of disease severity caused by $V$. dahliae isolates was computed.

\section{RESULTS}

PCR validation and sequencing of VdR2F-VdR2R amplicons. Specificity of the primer pair VdR2F-VdR2R was achieved in a 256-bp region containing 12 SNPs between Ls16 and Ls17 by designing the primers such that the binding sites within each primer differed from homologous sites in the nontarget race by at least two substitutions. Specifically, the forward primer VdR2F was designed to contain two substitutions, while the reverse primer VdR2R was designed to contain three substitutions (Fig. 1). Of the nine total primer pairs designed from variable primer binding sites, VdR2F-VdR2R was chosen because of its consistent amplification of DNA from known race 2 isolates and, importantly, its lack of specific amplification with DNA from known race 1 isolates. PCR results using Ave1F and Ave1R, Tr1 and $\operatorname{Tr} 2, \mathrm{VdR} 2 \mathrm{~F}$ and $\mathrm{VdR} 2 \mathrm{R}$, and DNA from 13 isolates of known race were concordant (Fig. 2A to $\mathrm{C}$ ). However, during preliminary comparisons, DNA from two isolates (isolates 40 and 79) amplified with the Avel-specific primers but failed to amplify with $\operatorname{Tr} 1-\operatorname{Tr} 2$. Therefore, VdAve1F and VdAve1R were chosen for race 1 characterizations. Sixty-seven VdR2F-VdR2R amplicons of $V$. dahliae race 2 strains were sequenced to confirm specific amplification of the target region, which is within an exon of a hypothetical protein (this region is present in the Ls16 race 1 genome but is polymorphic at the binding sites of the race 2specific primers). Three unique sequences (National Center for Biotechnology Information GenBank accession numbers KC935942 to KC935944) were observed among the set of amplicons at a frequency of 2, 11, and 54 sequences, respectively; none of the sequences exactly matched the reference strain sequence for Ls17 due to the presence of a single SNP that was not observed in any of the other alleles. Interestingly, the allele shared by 54 isolates included an insertion polymorphism, indicating a possible frameshift mutation.

Virulence of isolates on lettuce differential cultivars and verification by PCR. All 53 isolates yielded $\approx 256$-bp amplicons with VdR2F-VdR2R and failed to amplify with $\operatorname{Tr} 1-\operatorname{Tr} 2$ and Ave1F-Ave1R. The 53 isolates also induced severe wilt symptoms in both differential cultivars of lettuce (Table 1) suggesting that they belonged to race 2. V. dahliae was recovered from symptomatic roots plated on the semiselective NP-10 medium. Analysis of variance of the wilt severity indicated that there were significant differences between the isolates $(P \leq 0.003)$ and the isolate-cultivar interaction was significant $(P \leq 0.035)$. The wilt severity caused by the isolate Ls16 on La Brillante was 1.3 , which was the lowest disease severity value observed among the 55 isolates tested (Table 1). Similar to the reference race 2 isolate Ls17, all of the $53 \mathrm{~V}$. dahliae isolates from spinach seed caused extensive root discoloration on both Salinas and La Brillante (Table 1).

Race characterization of $V$. dahliae from commercial spinach seed production areas and commercial growing areas in coastal California and abroad. We characterized the races of $V$. dahliae isolates collected from spinach seed from Chile, Denmark, the Netherlands and the United States, as well as a broader, highly diverse sample from other crops and countries. The DNA from 96\% (327/340) of the isolates derived from spinach seed amplified with primers VdR2F-VdR2R and failed to amplify with VdAve1F-VdAve1R. Positive race 2 identification occurred on $100 \%$ of cotton isolates $(25 / 25), 13 \%$ of lettuce isolates (20/157), $100 \%$ of mint isolates (16/16), $74 \%$ of olive isolates (14/19), $83 \%$ of pepper isolates $(10 / 12), 100 \%$ of potato isolates $(13 / 13), 13 \%$ of strawberry isolates $(3 / 22), 100 \%$ of sunflower

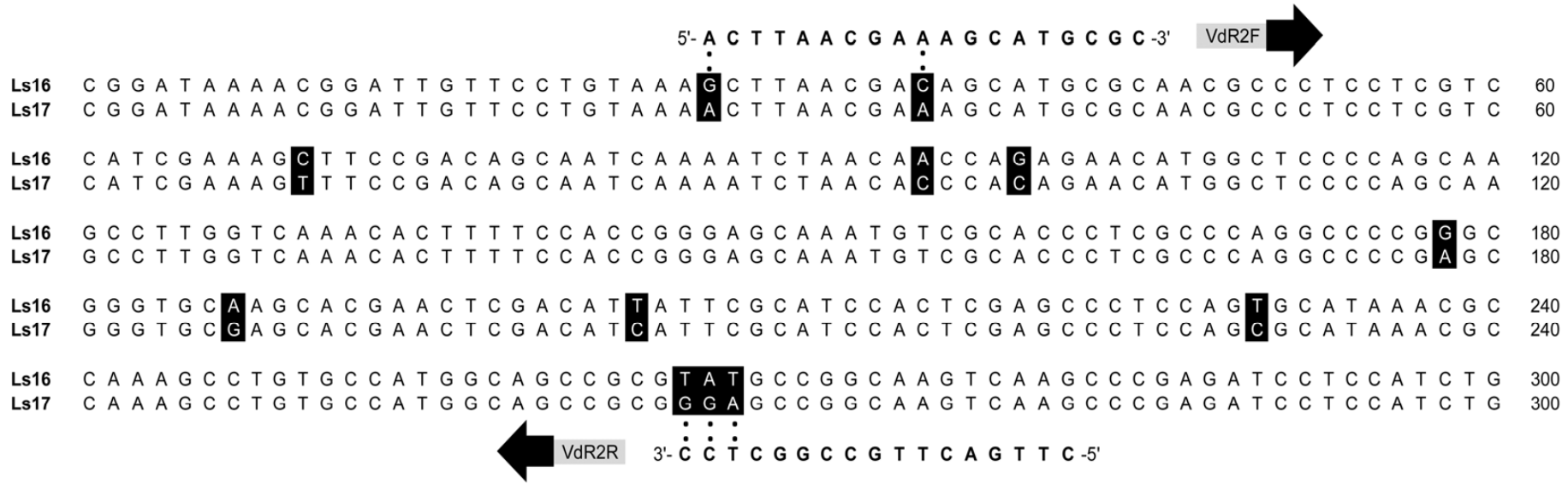

Fig. 1. Primer annealing sites of VdR2F-VdR2R shown with a nucleotide sequence alignment of the locus. Homologous 300-bp regions of the gene VDAG_05863 from two Verticillium dahliae isolates are shown: Ls16 (race 1) and Ls17 (race 2). Nucleotide polymorphisms are highlighted in black. The race-2-specific primers $\mathrm{VdR} 2 \mathrm{~F}$ and VdR2R are aligned with their respective annealing positions in the Ls17 genome. Primer mismatch sites between VdR2F-VdR2R and the Ls16 genome are indicated by two black dots. 
isolates (5/5), and $96 \%$ of tomato isolates (29/30), based on amplification with VdR2F-VdR2R and no amplification with Ave1F-Ave1R (Fig. 3). No DNA from artichoke isolates (0/34) amplified with VdR2F-VdR2R, whereas all (34/34) amplified with VdAve1F-VdAve1R, thus identifying them as race 1.

\section{DISCUSSION}

We used a comparative genomics approach to develop a PCR assay that yielded amplicons exclusively for $V$. dahliae race 2 DNA, based on a race-associated allele within a coding region of a hypothetical protein. The primer pair VdR2F-VdR2 selectively amplified a target present in race 2 DNA and did not amplify DNA from race 1 isolates. Although the primer pair $\operatorname{Tr} 1-\operatorname{Tr} 2$ (34) was also consistent with the results of VdR2F-VdR2R and VdAve1F-VdAve1R, we observed two cases where DNA amplified with VdAve1F-VdAve1R but failed to amplify with $\operatorname{Tr} 1-\operatorname{Tr} 2$ (isolates 40 and 79, gels not shown). We observed multiple allelic variants within the relatively small amplified region of $V D A G \_05863$, including SNPs and an insertion polymorphism. The allelic variants that constitute the primer binding sites themselves appear to harbor fixed substitutions between the two races. This is notable, because total sequence identity between $V$. dahliae race 1 and race 2 has been observed to be as high as $99.98 \%$ (7). The race 2 -specific primers were extensively validated on a diverse panel of isolates from a variety of crop hosts and geographic origins, and greenhouse experiments were consistent with the molecular results. Because the genetic basis of $V$. dahliae race 1 has been recently elucidated (8), we were able to compare the results of the two PCRs.

The PCR assays to characterize pathogenic races will not only enhance efforts to understand the ecology and population biology of $V$. dahliae but also will more readily enable studies on the ecology and distributions of the two races. In general, high pro- portions of race 2 were observed within most crops surveyed, although sample sizes varied considerably. Notable exceptions were the populations sampled from artichoke, lettuce, and strawberry, which largely comprised race 1 . We hypothesize that the isolates recovered from these three crops represent a single, persistent, and widespread $V$. dahliae population, because these crops have a history of successional rotation in the Coastal California growing regions studied. Pepper grown $\approx 40 \mathrm{~km}$ north and south of this general area is not grown in rotation with artichoke, lettuce, and strawberry, and the mixture of races recovered from pepper may reflect their relative isolation from these three crops.

Remarkably, $96 \%$ of the spinach seed isolates from multiple sources amplified only with the race- 2 specific PCR, highlighting imported spinach seed as a potential source of this race into Coastal California. However, it is important to note that, among the race 1 isolates from spinach seed and lettuce, identical 13locus microsatellite types have been recovered (S. Gurung, D. P. G. Short, and K. V. Subbarao, unpublished data), implicating spinach as one of the sources of $V$. dahliae introductions into areas where infested seed is planted. This hypothesis is also supported by the fact that spinach is planted at a density of 9 million seeds/ha, which makes the introduction of race 1 on infested spinach seed a more likely scenario. We also project that the immigration of $V$. dahliae associated with spinach seed may lead to an increase in the frequency of race 2 over time, especially in fields used for growing multiple crops of spinach. $V$. dahliae race 2 populations will likely have an impact on the race 1resistant cultivars currently in development, if pathogen populations are regularly introduced and eventually able to establish in agricultural soils. Currently, there appears to be a geographic demarcation of races in the lettuce-growing regions in Coastal California, because isolates from the Salinas Valley carried the Avel gene while isolates from Watsonville, where the disease was first observed, were of both races. Rapid assays for identifying the
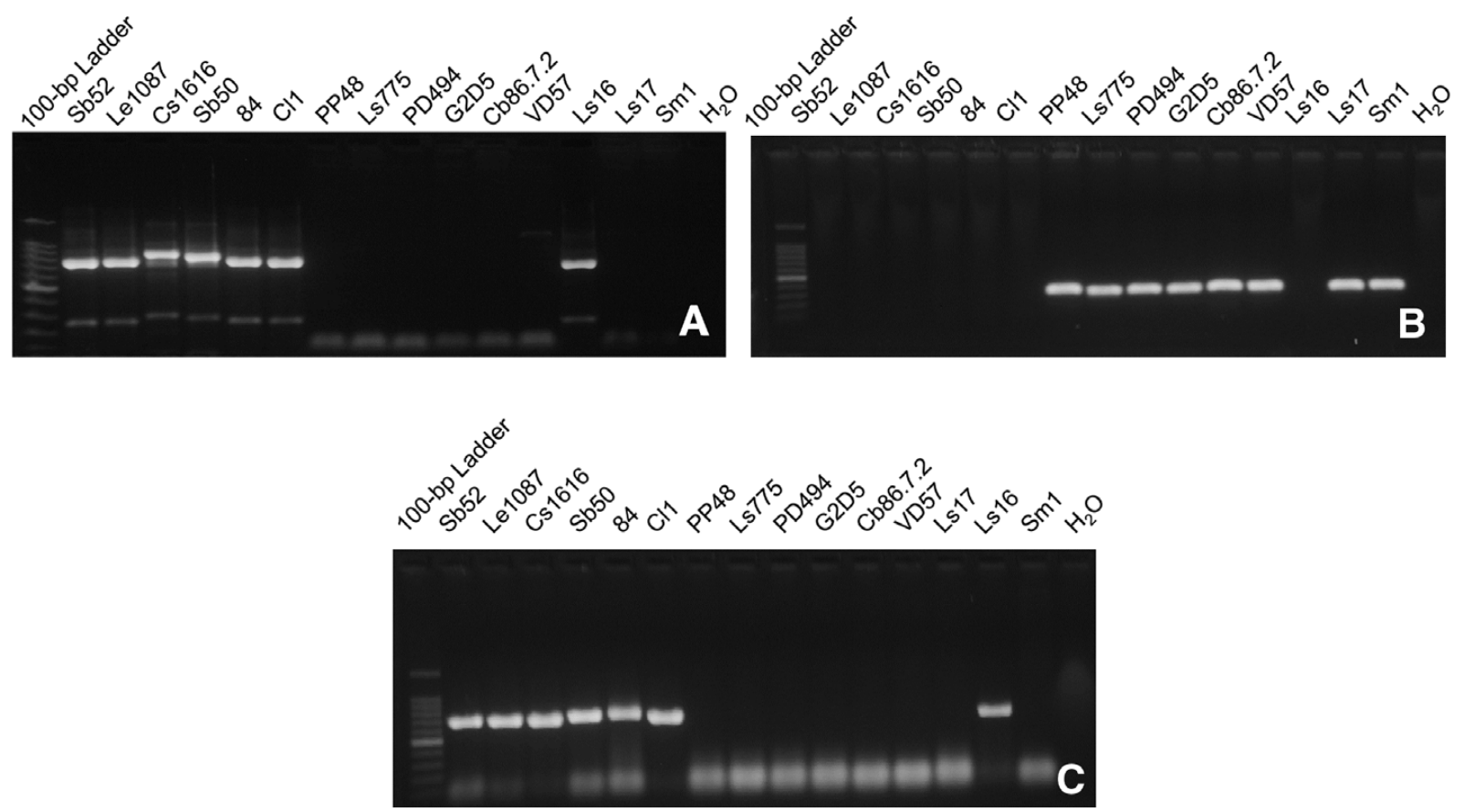

Fig. 2. Polymerase chain reaction amplicons generated with Verticillium dahliae race-specific primers. A, Amplicons generated with the race-1-specific primers VdAve1F and VdAve1R. B, Amplicons generated with the race-2-specific primers VdR2F and VdR2R. C, Amplicons generated with the race-1-specific primers $\operatorname{Tr} 1$ and $\operatorname{Tr} 2$. The gel was visualized on a 1.5\% (wt/vol) agarose gel; a 100-bp DNA ladder was included as a size marker. Isolate Sb52 collected from strawberry, California; isolate Le1087 collected from tomato, California; isolate Cs1616 collected from artichoke, California; isolate Sb50, collected from strawberry, California; isolate 84 collected from spinach seed, Washington; isolate Cl1, collected from watermelon, California; isolate PP48 collected from cotton, Australia; isolate Ls775 collected from lettuce, California; isolate PD494 collected from strawberry, California; isolate G2D5 collected from spinach seed, Washington; Cb86.7.2 collected from potato, Washington; isolate VD57, collected from mint, Washington; isolate Ls16 collected from lettuce, California; isolate Ls17 collected from lettuce, California; isolate Sm1, collected from eggplant, California. Ls16 and Ls17 were used as positive controls for race 1 and race 2, respectively. Sterile distilled water was used a negative control. 
race of $V$. dahliae may help determine planting decisions by growers and will be useful in tracking the spread of race 2 across Coastal California.

The molecular surveys of $V$. dahliae in the current study concur with previous studies on the variability in race structure that is observable at small scales (21). Although the global migration of genotypes in $V$. dahliae has likely occurred and continues to play an important role in the diversification of fungal populations, within-field variation may be low and may be dominated by widespread clonal types. Thus, race structure in specific crops and commodities may exist, depending on the geography. For example, all the artichoke isolates tested from California were

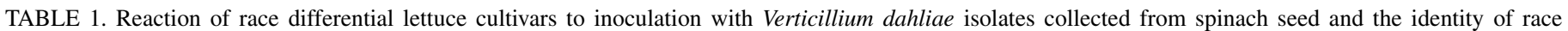
deduced using race-2-specific primer pairs VdR2F-VdR2R and VdAve1F-VdAve1R

\begin{tabular}{|c|c|c|c|c|c|c|c|}
\hline \multirow{3}{*}{$\begin{array}{l}\text { Sample } \\
\text { number }\end{array}$} & \multirow[b]{3}{*}{ Isolate } & \multicolumn{4}{|c|}{ Root and crown discoloration ${ }^{\mathrm{a}}$} & & \\
\hline & & \multicolumn{2}{|c|}{ Salinas $^{b}$} & \multicolumn{2}{|c|}{ La Brillante ${ }^{\mathrm{b}}$} & \multicolumn{2}{|c|}{ Race designation $^{\mathrm{c}}$} \\
\hline & & Mean & Median & Mean & Median & Pathogenicity assays & Primers \\
\hline 1 & 1 & $3.2(0.1)$ & $3.3(0.1)$ & $3.1(0.3)$ & $3.0(0.3)$ & Race 2 & Race 2 \\
\hline 2 & 2 & $3.3(0.2)$ & $3.3(0.2)$ & $3.3(0.4)$ & $3.3(0.5)$ & Race 2 & Race 2 \\
\hline 3 & 3 & $3.3(0.5)$ & $3.0(0.6)$ & $2.8(0.1)$ & $2.7(0.1)$ & Race 2 & Race 2 \\
\hline 4 & 5 & $2.7(0.2)$ & $2.7(0.2)$ & $3.1(0.3)$ & $3.0(0.3)$ & Race 2 & Race 2 \\
\hline 5 & 27 & $2.8(0.2)$ & $3.0(0.2)$ & $3.3(0.2)$ & $3.3(0.2)$ & Race 2 & Race 2 \\
\hline 6 & 29 & $2.6(0.1)$ & $2.7(0.1)$ & $3.4(0.4)$ & $3.0(0.5)$ & Race 2 & Race 2 \\
\hline 7 & 31 & $3.1(0.2)$ & $3.3(0.2)$ & $3.2(0.1)$ & $3.3(0.1)$ & Race 2 & Race 2 \\
\hline 8 & 33 & $3.1(0.1)$ & $3.0(0.1)$ & $4.3(0.2)$ & $4.3(0.2)$ & Race 2 & Race 2 \\
\hline 9 & 40 & $3.3(0.4)$ & $3.3(0.5)$ & $4.0(0.3)$ & $3.7(0.3)$ & Race 2 & Race 2 \\
\hline 10 & 42 & $2.9(0.1)$ & $3.0(0.1)$ & $3.4(0.1)$ & $3.3(0.1)$ & Race 2 & Race 2 \\
\hline 11 & 53 & $3.5(0.2)$ & $3.7(0.2)$ & $4.0(0.5)$ & $4.3(0.6)$ & Race 2 & Race 2 \\
\hline 12 & 58 & $3.3(0.2)$ & $3.3(0.2)$ & $3.6(0.4)$ & $4.0(0.5)$ & Race 2 & Race 2 \\
\hline 13 & 67 & $3.2(0.3)$ & $3.3(0.3)$ & $3.6(0.6)$ & $3.3(0.7)$ & Race 2 & Race 2 \\
\hline 14 & 145 & $3.8(0.3)$ & $3.7(0.3)$ & $4.6(0.2)$ & $4.7(0.2)$ & Race 2 & Race 2 \\
\hline 15 & 146 & $3.3(0.2)$ & $3.3(0.2)$ & $3.6(0.4)$ & $3.3(0.5)$ & Race 2 & Race 2 \\
\hline 16 & 149 & $3.2(0.2)$ & $3.0(0.2)$ & $3.8(0.4)$ & $4.0(0.5)$ & Race 2 & Race 2 \\
\hline 17 & 150 & $3.3(0.2)$ & $3.3(0.2)$ & $3.2(0.1)$ & $3.3(0.1)$ & Race 2 & Race 2 \\
\hline 18 & 152 & $3.2(0.4)$ & $3.0(0.5)$ & $3.2(0.1)$ & $3.3(0.1)$ & Race 2 & Race 2 \\
\hline 19 & 154 & $2.8(0.1)$ & $2.7(0.1)$ & $2.6(0.3)$ & $2.7(0.3)$ & Race 2 & Race 2 \\
\hline 20 & 163 & $4.0(0.5)$ & $3.7(0.6)$ & $3.0(0.0)$ & $3.0(0.0)$ & Race 2 & Race 2 \\
\hline 21 & G1A4 & $2.6(0.1)$ & $2.7(0.1)$ & $3.9(0.2)$ & $3.7(0.2)$ & Race 2 & Race 2 \\
\hline 22 & G1B1 & $2.4(0.1)$ & $2.3(0.1)$ & $4.1(0.2)$ & $4.0(0.2)$ & Race 2 & Race 2 \\
\hline 23 & G1C4 & $2.6(0.4)$ & $2.3(0.5)$ & $3.3(0.3)$ & $3.7(0.3)$ & Race 2 & Race 2 \\
\hline 24 & G1C5 & $2.6(0.1)$ & $2.7(0.1)$ & $2.9(0.3)$ & $3.0(0.3)$ & Race 2 & Race 2 \\
\hline 25 & G1D1 & $2.7(0.3)$ & $2.3(0.3)$ & $3.1(0.2)$ & $3.3(0.2)$ & Race 2 & Race 2 \\
\hline 26 & G1D3 & $2.9(0.6)$ & $2.3(0.7)$ & $3.7(0.2)$ & $3.7(0.2)$ & Race 2 & Race 2 \\
\hline 27 & G1D7 & $3.0(0.2)$ & $3.0(0.2)$ & $2.8(0.3)$ & $2.7(0.3)$ & Race 2 & Race 2 \\
\hline 28 & G1E1 & $2.8(0.1)$ & $2.7(0.1)$ & $3.7(0.5)$ & $4.0(0.6)$ & Race 2 & Race 2 \\
\hline 29 & G1E3 & $2.7(0.2)$ & $2.7(0.2)$ & $4.2(0.1)$ & $4.3(0.1)$ & Race 2 & Race 2 \\
\hline 30 & G1E4 & $2.7(0.2)$ & $2.7(0.2)$ & $3.3(0.5)$ & $3.0(0.6)$ & Race 2 & Race 2 \\
\hline 31 & G2A1 & $2.8(0.1)$ & $2.7(0.1)$ & $3.0(0.2)$ & $3.0(0.2)$ & Race 2 & Race 2 \\
\hline 32 & G2A2 & $2.9(0.3)$ & $3.0(0.3)$ & $3.2(0.5)$ & $3.7(0.6)$ & Race 2 & Race 2 \\
\hline 33 & G2A3 & $2.7(0.2)$ & $2.7(0.2)$ & $2.7(0.5)$ & $2.3(0.6)$ & Race 2 & Race 2 \\
\hline 34 & G2A4 & $2.4(0.1)$ & $2.3(0.1)$ & $2.8(0.3)$ & $2.7(0.3)$ & Race 2 & Race 2 \\
\hline 35 & G2B1 & $2.7(0.2)$ & $2.7(0.2)$ & $3.4(0.3)$ & $3.3(0.3)$ & Race 2 & Race 2 \\
\hline 36 & G2B9 & $2.9(0.2)$ & $2.7(0.2)$ & $2.8(0.2)$ & $3.0(0.2)$ & Race 2 & Race 2 \\
\hline 37 & $\mathrm{G} 2 \mathrm{C} 1$ & $2.6(0.3)$ & $2.7(0.3)$ & $3.3(0.4)$ & $3.3(0.5)$ & Race 2 & Race 2 \\
\hline 38 & $\mathrm{G} 2 \mathrm{C} 3$ & $2.9(0.3)$ & $3.0(0.3)$ & $3.1(0.2)$ & $3.0(0.2)$ & Race 2 & Race 2 \\
\hline 39 & G2C5 & $2.8(0.4)$ & $3.0(0.5)$ & $2.8(0.5)$ & $2.3(0.6)$ & Race 2 & Race 2 \\
\hline 40 & G2D2 & $3.4(0.1)$ & $3.3(0.1)$ & $3.3(0.2)$ & $3.3(0.2)$ & Race 2 & Race 2 \\
\hline 41 & G2D4 & $3.1(0.2)$ & $3.3(0.2)$ & $3.2(0.4)$ & $3.0(0.5)$ & Race 2 & Race 2 \\
\hline 42 & G2D5 & $3.0(0.5)$ & $2.7(0.6)$ & $3.2(0.1)$ & $3.3(0.1)$ & Race 2 & Race 2 \\
\hline 43 & G2D9 & $3.3(0.2)$ & $3.3(0.2)$ & $3.3(0.5)$ & $3.0(0.6)$ & Race 2 & Race 2 \\
\hline 44 & G3A1 & $3.2(0.5)$ & $3.3(0.6)$ & $3.0(0.5)$ & $2.7(0.6)$ & Race 2 & Race 2 \\
\hline 45 & G3A2 & $3.1(0.3)$ & $3.0(0.3)$ & $3.4(0.6)$ & $3.7(0.7)$ & Race 2 & Race 2 \\
\hline 46 & G3A4 & $3.0(0.2)$ & $3.0(0.2)$ & $2.9(0.2)$ & $2.7(0.2)$ & Race 2 & Race 2 \\
\hline 47 & G3B3 & $2.7(0.2)$ & $2.7(0.2)$ & $3.7(0.5)$ & $4.0(0.6)$ & Race 2 & Race 2 \\
\hline 48 & G3B4 & $3.0(0.0)$ & $3.0(0.0)$ & $3.4(0.5)$ & $3.3(0.6)$ & Race 2 & Race 2 \\
\hline 49 & G3C2 & $2.7(0.2)$ & $2.7(0.2)$ & $2.9(0.4)$ & $2.7(0.5)$ & Race 2 & Race 2 \\
\hline 50 & G3D3 & $2.7(0.3)$ & $2.3(0.3)$ & $4.2(0.1)$ & $4.3(0.1)$ & Race 2 & Race 2 \\
\hline 51 & G3E1 & $2.7(0.2)$ & $2.7(0.2)$ & $3.3(0.8)$ & $2.7(0.9)$ & Race 2 & Race 2 \\
\hline 52 & G3E3 & $2.8(0.3)$ & $2.7(0.3)$ & $3.8(0.2)$ & $4.0(0.2)$ & Race 2 & Race 2 \\
\hline 53 & G3E5 & $3.2(0.2)$ & $3.0(0.2)$ & $4.0(0.5)$ & $4.3(0.6)$ & Race 2 & Race 2 \\
\hline 54 & Ls16 & $2.6(0.4)$ & $3.0(0.5)$ & $1.0(0.3)$ & $1.3(0.3)$ & Race 1 & Race 1 \\
\hline 55 & Ls17 & $3.4(0.1)$ & $3.3(0.1)$ & $2.9(0.2)$ & $2.3(0.2)$ & Race 2 & Race 2 \\
\hline Control & $\ldots$ & 0.00 & 0.00 & 0.00 & 0.00 & $\ldots$ & $\ldots$ \\
\hline
\end{tabular}

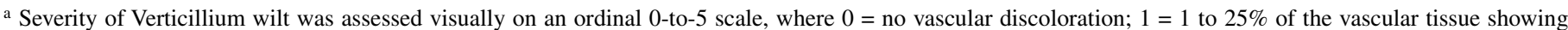
discoloration; $2=26$ to $50,3=51$ to 75 , and $4=76$ to $100 \%$ discoloration in the absence of foliar symptoms; and $5=100 \%$ discoloration and the presence of foliar symptoms typical of Verticillium wilt after Hayes et al. (18). Values within the parentheses are standard errors of the mean or median.

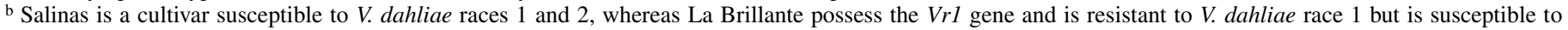
$V$. dahliae race 2 isolates.

c Race designation based on reaction to lettuce differential lines (pathogenicity assays) and race-specific primers. 


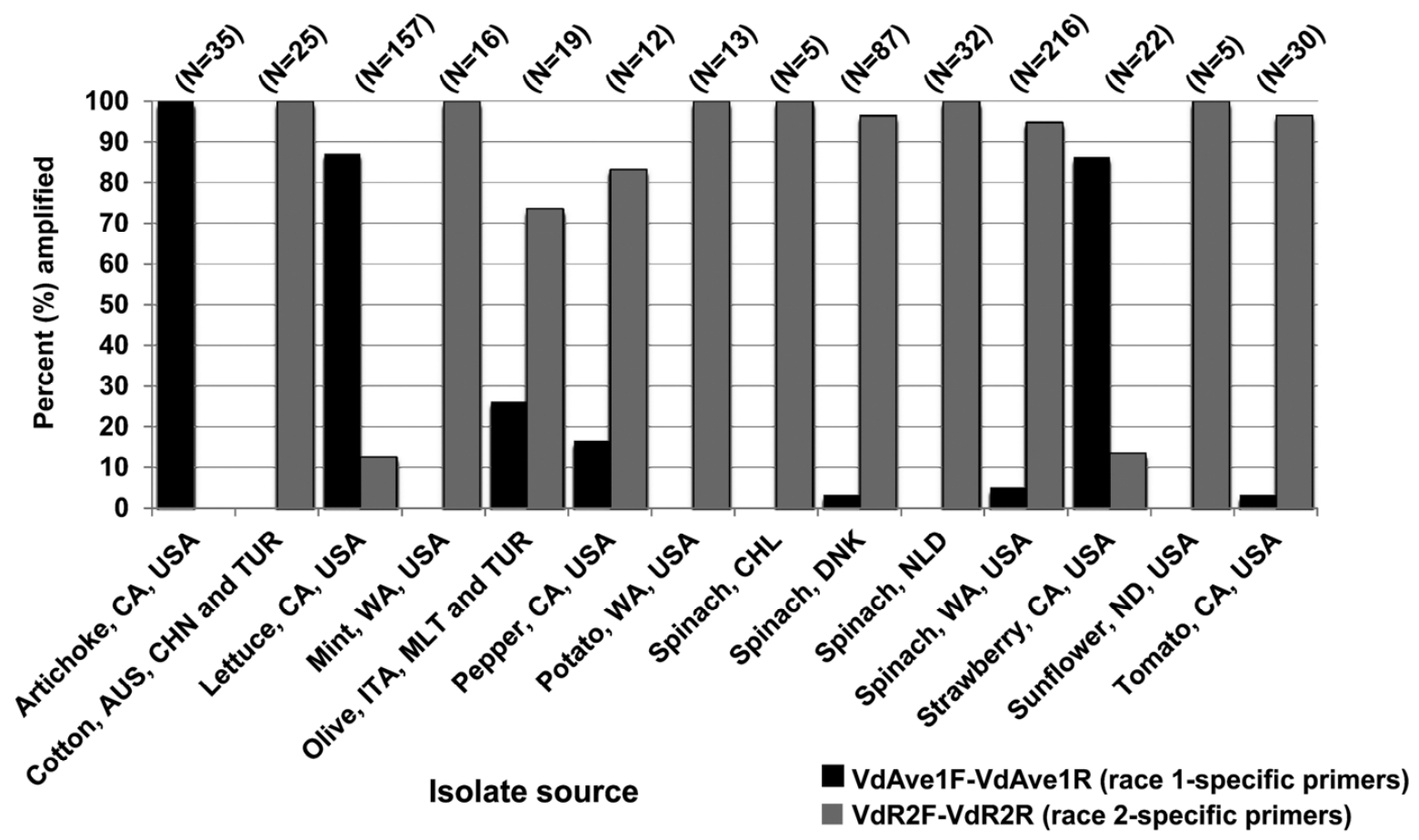

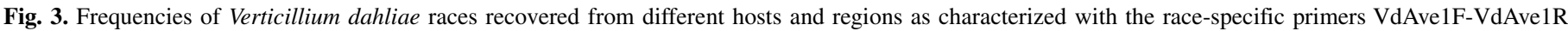

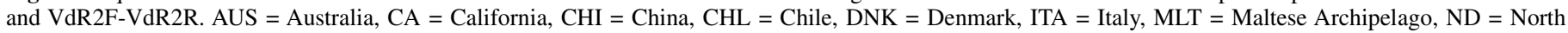
Dakota, NLD = The Netherlands, TUR=Turkey. Two Italian $V$. dahliae isolates, from almond and cherry, respectively, are not shown.

race 1 , though race 2 artichoke isolates from Tunisia have been reported (21). Similarly, the races of olive isolates from Italy and the Maltese Archipelago showed affiliation with geographic origin; all olive isolates from Italy were race 1, whereas all olive isolates from the Maltese Archipelago were race 2. Likewise, in the current study, all of the mint and potato isolates were race 2 and were collected from Washington State, where spinach seed production occurs.

Variability in race structure is likely influenced by the deployment of plant $R$ genes. The $V e$ gene, first identified in tomato in the 1950s (32) and widely deployed in commercial cultivars since the late 1960s, likely applied a strong selection pressure on $V$. dahliae populations. This hypothesis is supported by the fact that all but one (Le1087) of the tomato isolates characterized in the current study were race 2 (Le1087 is a $V$. dahliae race 1 reference isolate from California collected in the 1950s). In an earlier survey of both plant tissue and soil collected from race 1-resistant tomato cultivars and production fields, the frequency of race 2 was $86 \%(n=153)$ (17). Among the other crops surveyed from Coastal California in the current study, both races were also observed among the isolates derived from lettuce, pepper, and strawberry. Even though well-defined host-race interactions have only been described in cotton, lettuce, sunflower, and tomato because of the availability of host differentials $(15,20,32,38)$, this study documented that the two races exist among isolates from other crops, including olive, pepper, and strawberry. Our inability to identify races in other crops hitherto was limited only by the lack of host resistance in these crops and the corresponding host differentials. The primers developed in this study provide a means to increase our understanding of race structure in other crops. The general lack of host specificity in $V$. dahliae suggests that isolates from one crop are capable of causing disease in others (5); therefore, it stands to reason that, once established in a given geographic area, both races can cause wilt disease in a range of crops grown in that area. Thus, an isolate described as originating from a particular host may simply reflect the pathogen reservoir present in the soil used to cultivate the crop. In the current study, this could have played a role in the identification of the two races from crops other than cotton, lettuce, sunflower, and tomato, despite the absence of host resistance in other crops.

The presence of both races in growing regions has been observed for several decades in North America $(4,10)$, though it is unclear to what extent selection is driving the evolution of pathogen populations. Race 2 is hypothesized to have originated from race 1 through the loss of Avel (8). Whether or not this has occurred multiple times over many geographic scales remains unclear but it appears to be a distinct possibility, because several studies have documented the shared genotypes among isolates of different races (11). Further studies on the microevolution of $V$. dahliae race within a single field are needed to assess the potential for rapid shifts in race structure due to selection. The use of the PCR technique developed in this study will improve future pathogen population biology studies and highlight the importance of breeding efforts to develop resistance in lettuce and other crops against $V$. dahliae race 2 .

\section{ACKNOWLEDGMENTS}

Funding for this study was provided by United States Department of Agriculture NIFA-SCRI grant number 2010-51181-21069 and by the California Leafy Greens Research Board. D. P. G. Short and S. Gurung contributed equally to this work. We thank S. Benlioglu, R. M. Davis, L. du Toit, D. A. Johnson, K. Kirkby, G. Q. Li, S. Markel, and F. Nigro for providing isolates for this study; P. Inderbitzin for suggestions on the study; and R. Marchebout for excellent technical assistance.

\section{LITERATURE CITED}

1. Atallah, Z. K., Hayes, R. J., and Subbarao, K. V. 2011. Fifteen years of Verticillium wilt of lettuce in America's salad bowl: a tale of immigration, subjugation, and abatement. Plant Dis. 95:784-792.

2. Atallah, Z. K., Maruthachalam, K., and Subbarao, K. V. 2012. Sources of Verticillium dahliae affecting lettuce. Phytopathology 102:1071-1078.

3. Baergen, K., Hewitt, J., and Clair, D. S. 1993. Resistance of tomato genotypes to four isolates of Verticillium dahliae race 2. HortScience 28:833-836.

4. Bender, C., and Shoemaker, P. 1984. Prevalence of Verticillium wilt of 
tomato and virulence of Verticillium dahliae race 1 and race 2 isolates in western North Carolina. Plant Dis. 68:305-309.

5. Bhat, R., and Subbarao, K. 1999. Host range specificity in Verticillium dahliae. Phytopathology 89:1218-1225.

6. Boller, T., and He, S. Y. 2009. Innate immunity in plants: an arms race between pattern recognition receptors in plants and effectors in microbial pathogens. Science 324:742-744.

7. de Jonge, R., Bolton, M., Kombrink, A., van den Berg, G., Yadeta, K., and Thomma, B. 2013. Extensive chromosomal reshuffling drives evolution of virulence in an asexual pathogen. Genome Res. 23:1271-1282.

8. de Jonge, R., van Esse, H. P., Maruthachalam, K., Bolton, M. D., Santhanam, P., Saber, M. K., Zhang, Z., Usami, T., Lievens, B., and Subbarao, K. V. 2012. Tomato immune receptor $V e 1$ recognizes effector of multiple fungal pathogens uncovered by genome and RNA sequencing. Proc. Natl. Acad. Sci. USA 109:5110-5115.

9. De Wit, P. J. 1997. Pathogen avirulence and plant resistance: a key role for recognition. Trends Plant Sci. 2:452-458.

10. Dobinson, K., Tenuta, G., and Lazarovits, G. 1996. Occurrence of race 2 of Verticillium dahliae in processing tomato fields in southwestern Ontario. Can. J. Plant Pathol. 18:55-58.

11. Dobinson, K. F., Patterson, N. A., White, G. J., and Grant, S. 1998. DNA fingerprinting and vegetative compatibility analysis indicate multiple origins for Verticillium dahliae race 2 tomato isolates from Ontario, Canada. Mycol. Res. 102:1089-1095.

12. Dung, J. K., Hamm, P. B., Eggers, J. E., and Johnson, D. A. 2013. Incidence and impact of Verticillium dahliae in soil associated with certified potato seed lots. Phytopathology 103:55-63.

13. du Toit, L. J., Derie, M. L., and Hernandez-Perez, P. 2005. Verticillium wilt in spinach seed production. Plant Dis. 89:4-11.

14. Ferreira, J., Merwe, P., and Naude, S. 1990. First report of race 2 of Verticillium dahliae on tomatoes in South Africa. Plant Dis. 74:530.

15. Fick, G., and Zimmer, D. 1974. Monogenic resistance to Verticillium wilt in sunflowers. Crop Sci. 14:895-896.

16. Fisher, M. C., Henk, D. A., Briggs, C. J., Brownstein, J. S., Madoff, L. C., McCraw, S. L., and Gurr, S. J. 2012. Emerging fungal threats to animal, plant and ecosystem health. Nature 484:186-194.

17. Grogan, R., Ioannou, N., Schneider, R., Sall, M., and Kimble, K. 1979. Verticillium wilt on resistant tomato cultivars in California: virulence of isolates from plants and soil and relationship of inoculum density to disease incidence. Phytopathology 69:1176-1180.

18. Hayes, R. J., Maruthachalam, K., Vallad, G. E., Klosterman, S. J., and Subbarao, K. V. 2011. Selection for resistance to Verticillium wilt caused by race 2 isolates of Verticillium dahliae in accessions of lettuce (Lactuca sativa L.). HortScience 46:201-206.

19. Hayes, R. J., McHale, L. K., Vallad, G. E., Truco, M. J., Michelmore, R. W., Klosterman, S. J., Maruthachalam, K., and Subbarao, K. V. 2011. The inheritance of resistance to Verticillium wilt caused by race 1 isolates of Verticillium dahliae in the lettuce cultivar La Brillante. Theor. Appl. Genet. 123:509-517.

20. Hayes, R. J., Vallad, G. E., Qin, Q.-M., Grube, R. C., and Subbarao, K. V. 2007. Variation for resistance to Verticillium wilt in lettuce (Lactuca sativa L.). Plant Dis. 91:439-445.

21. Jabnoun-Khiareddine, H., Daami-Remadi, M., and El Mahjoub, M. 2013. Status of Verticillium dahliae race 2 in Tunisia. Page 134 in: 11 th Int.
Verticillium Symp. B. Koopmann and A. von Tiedemann, eds. Göttingen, Germany.

22. Kabir, Z., Bhat, R., and Subbarao, K. 2004. Comparison of media for recovery of Verticillium dahliae from soil. Plant Dis. 88:49-55.

23. Klosterman, S. J., Subbarao, K. V., Kang, S., Veronese, P., Gold, S. E., Thomma, B. P., Chen, Z., Henrissat, B., Lee, Y.-H., and Park, J. 2011. Comparative genomics yields insights into niche adaptation of plant vascular wilt pathogens. PLoS Pathog. 7:e1002137.

24. Kumar, S., Nei, M., Dudley, J., and Tamura, K. 2008. MEGA: a biologistcentric software for evolutionary analysis of DNA and protein sequences. Brief. Bioinf. 9:299-306.

25. Maruthachalam, K., Atallah, Z., Vallad, G., Klosterman, S., Hayes, R., Davis, R. M., and Subbarao, K. 2010. Molecular variation among isolates of Verticillium dahliae and polymerase chain reaction-based differentiation of races. Phytopathology 100:1222-1230.

26. Maruthachalam, K., Park, J., Lee, Y.-H., and Subbarao, K. V. 2011. Sequencing of Verticillium dahliae race 1 using Illumina short sequence reads and comparative genomics of Verticillium. In: Plant and Animal Genomes XIX Conference, San Diego, CA.

27. McDonald, B. A., and Linde, C. 2002. Pathogen population genetics, evolutionary potential, and durable resistance. Annu. Rev. Phytopathol. 40:349-379.

28. Nachmias, A., Buchner, V., Tsror, L., Burstein, Y., and Keen, N. 1987. Differential phytotoxicity of peptides from culture fluids of Verticillium dahliae races 1 and 2 and their relationship to pathogenicity of the fungi on tomato. Phytopathology 77:506-510.

29. O'Brien, R., and Hutton, D. 1981. Identification of race 2 of Verticillium wilt in tomatoes in south-east Queensland. Australas. Plant Pathol. 10:5658.

30. Park, J., Park, B., Jung, K., Jang, S., Yu, K., Choi, J., Kong, S., Park, J., Kim, S., and Kim, H. 2008. CFGP: a web-based, comparative fungal genomics platform. Nucleic Acids Res. 36:D562-D571.

31. Pegg, G., and Brady, B. 2002. Verticillium Wilts. CAB International. Oxford.

32. Schaible, L., Cannon, O. S., and Waddoups, V. 1951. Inheritance of resistance to Verticillium wilt in a tomato cross. Phytopathology 41:986990.

33. Shah, D., and Madden, L. 2004. Nonparametric analysis of ordinal data in designed factorial experiments. Phytopathology 94:33-43.

34. Usami, T., Ishigaki, S., Takashina, H., Matsubara, Y., and Amemiya, Y. 2007. Cloning of DNA fragments specific to the pathotype and race of Verticillium dahliae. J. Gen. Plant Pathol. 73:89-95.

35. Vallad, G. E., Bhat, R. G., Koike, S. T., Ryder, E. J., and Subbarao, K. V. 2005. Weedborne reservoirs and seed transmission of Verticillium dahliae in lettuce. Plant Dis. 89:317-324.

36. Vallad, G. E., Qin, Q.-M., Grube, R., Hayes, R. J., and Subbarao, K. V. 2006. Characterization of race-specific interactions among isolates of Verticillium dahliae pathogenic on lettuce. Phytopathology 96:1380-1387.

37. Zhang, J., and Zhou, J.-M. 2010. Plant immunity triggered by microbial molecular signatures. Mol. Plant 3:783-793.

38. Zhang, Y., Wang, X., Yang, S., Chi, J., Zhang, G., and Ma, Z. 2011. Cloning and characterization of a Verticillium wilt resistance gene from Gossypium barbadense and functional analysis in Arabidopsis thaliana. Plant Cell Rep. 30:2085-2096.

\section{Erratum}

Changes were made to the last paragraph of the Results section on page 781. Changes to this article were made on June 25, 2014. 